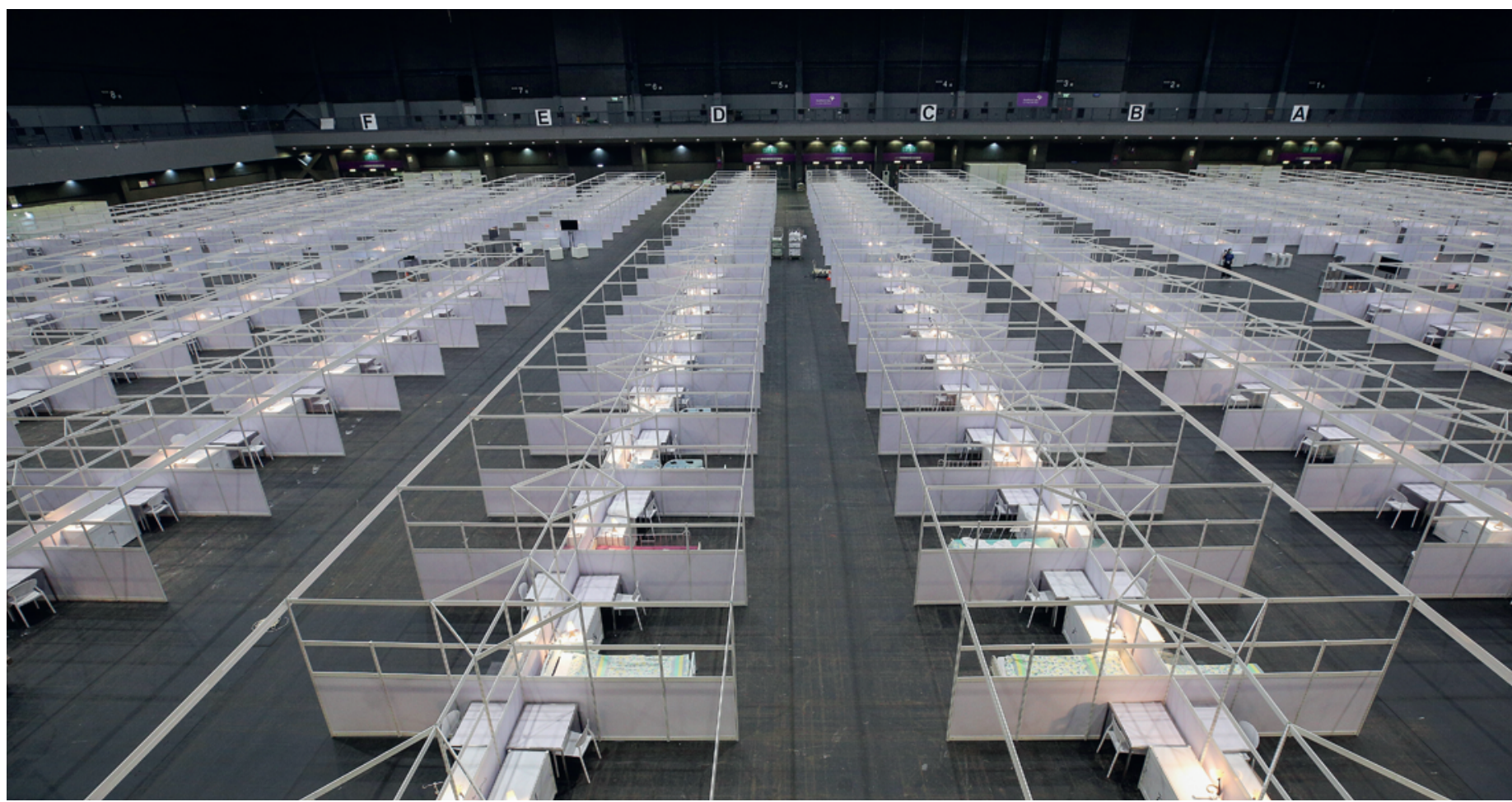

Die Hallen des Asia World Expo Kongresszentrums, umgewandelt in ein provisorisches Spital für Covid-19-Patientinnen und -Patienten, die keinen medizinischen Eingriff benötigen.

(C) Spitalbehörde Hongkong

\title{
Wie Hongkong das Virus in Schach hielt
}

\section{Julie Zaugg}

Freischaffende Journalistin

Die Hafenstadt Hongkong hat es dank eines Cocktails aus radikalen Massnahmen weitgehend geschafft, Covid-19 einzudämmen. Diese wurden im Zuge der SARSPandemie entwickelt und gingen teils auf Kosten der Freiheit und des Wohlbefindens der Bevölkerung. Drei Ärzte erzählen.

Die Schaltzentrale des provisorischen Spitals in den riesigen Hallen der Asia World Expo, einem Kongresszentrum unweit des Hongkonger Flughafens, sieht an diesem Februarnachmittag aus wie ein geschäftiger Bienenstock. Ein paar Ärztinnen und Ärzte in weissen Kitteln besprechen in einer Ecke des grossen neonbeleuchteten Raums die Vorkommnisse des Tages. Die Pflegefachpersonen analysieren ExcelDateien, in denen der Gesundheitszustand aller hier untergebrachten Menschen festgehalten wird. Das Sicherheitspersonal schaut sich die Bilder der Überwachungskameras auf einem riesigen Bildschirm an, der Dutzende von Bettenreihen zeigt, die durch herausnehmbare Wände getrennt sind.
"Wir nehmen alle auf, die positiv auf Covid-19 getestet wurden, aber nur leichte oder gar keine Symptome zeigen", sagt Larry Lee, der leitende Arzt des Zentrums. Aufgenommen werden infizierte Personen, die keinen medizinischen Eingriff benötigen. «Das temporäre Spital bietet Platz für 900 Patientinnen und Patienten. Aber im Moment sind nur 80 Betten belegt», erzählt der 48-jährige Mediziner, der normalerweise eine Einrichtung in einem Vorort von Hongkong mitbetreibt. In einem anderen Flügel des Kongresszentrums findet die Triage statt. Die Erkrankten werden in vorläufige (ein positiver Test) und bestätigte (zwei positive Tests) Fälle getrennt. Sobald die Infektion bestätigt ist, werden sie mit einem Shuttlebus in das provisorische Spital trans- 
portiert. Dort müssen sie bleiben, bis das Virus nicht mehr in ihrem Speichel nachweisbar ist oder ein Bluttest das Vorhandensein von Antikörpern zeigt. Während ihres Aufenthalts, der durchschnittlich zehn Tage dauert, dürfen sie das Spitalgelände nicht verlassen.

\section{Die Lehren aus der SARS-Pandemie}

«Wir haben im vergangenen März begonnen, ein solches Zentrum in Erwägung zu ziehen. Zu diesem Zeitpunkt ist die Zahl der Fälle in Singapur, einem kleinen, dicht besiedelten Gebiet mit ähnlichen Merkmalen wie Hongkong, explodiert», sagt Larry Lee. "Wir wissen, dass fast 70 Prozent der Fälle mild oder asymptomatisch verlaufen. Daher hielten wir es für entscheidend, die Spitäler die nur über 1500 Isolierbetten verfügen - zu entlasten. Aus diesem Grund werden Menschen mit unkompliziertem Verlauf in einer temporären Einrichtung weit weg vom Stadtzentrum untergebracht», fährt er fort.

Die SARS-Epidemie im Jahr 2003 machte der lokalen Ärzteschaft klar, dass das Spitalsystem um jeden Preis vor dem Kollaps bewahrt werden muss. Nur so könne die Sterblichkeitsrate niedrig gehalten werden, meint Lee, der vor 18 Jahren noch ein junger Notarzt war.

Überraschend für alle traf die zweite Welle der CovidPandemie Hongkong bereits im Sommer 2020. «Wir mussten das Spital in weniger als 72 Stunden wieder zum Laufen bringen", erinnert er sich. Ende Februar wurde die Infrastruktur erweitert. Ein neues Zentrum für intermediäre Fälle, also solche, die eine antivirale Behandlung oder eine Sauerstoffversorgung mit geringer Intensität benötigen, kam in einer Reihe von Fertighäusern hinzu.

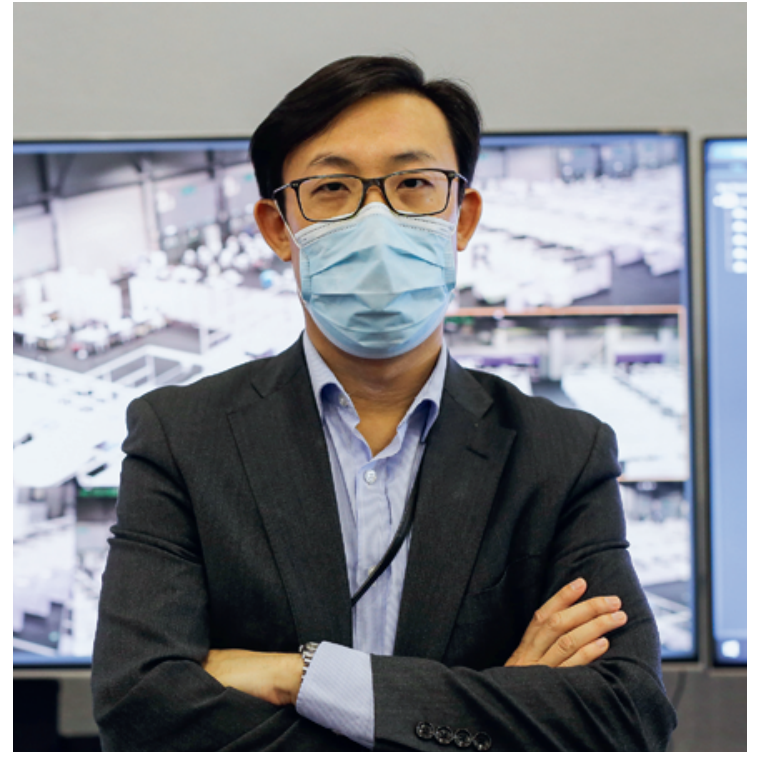

Larry Lee leitet das provisorische Spital beim Asia World Expo. Die Einrichtung wurde in 72 Stunden auf die Beine gestellt, als die Covid-19-Fälle letzten Sommer zu steigen begannen.

(c) Julie Zaugg

Diese temporären Strukturen, die es Hongkong ermöglicht haben, jeden entdeckten Fall von Covid-19 zu isolieren, sind nur ein Bestandteil einer gut funktionierenden Strategie, die nach der SARS-Pandemie eingeführt wurde. Diese Strategie ermöglichte es, einen harten Lockdown in der Hafenstadt zu vermeiden. Die Restaurants, Geschäfte und sogar Vergnügungsparks waren während eines Grossteils der Pandemie geöffnet. Hongkong verzeichnete nur 10897 Covid-19-Fälle und 197 Todesfälle bei einer ähnlichen Bevölkerungszahl wie die Schweiz.

\section{Die Polizei geht von Tür zu Tür}

Die spektakulärste Massnahme bleibt, ganze Stadtteile für 48 Stunden abzuriegeln, um alle zu testen. Im Januar errichteten 3000 Polizeibeamte einen SeuchenschutzSperrgürtel um Yau Tsim Mong, eines der am dichtesten besiedelten Viertel der Welt. Die Beamten gingen von Tür zu Tür, um Proben der 7000 Bewohner zu sammeln. Den Anwohnerinnen und Anwohnern wurde strikt untersagt, ihre Häuser für die Dauer des Einsatzes zu verlassen. Angekündigt nur wenige Minuten bevor die Zwangseinweisungen in Kraft treten sollten, sorgten sie für einigen Unmut in der Bevölkerung. Bei einem dieser Einsätze waren beispielsweise mehrere Personen, darunter ein 11-jähriges Mädchen, über einen Grossteil der Nacht in einem Coiffeursalon eingeschlossen.

«Das Verhältnis zwischen den Kosten der Massnahmen und ihrer Wirksamkeit lässt ebenfalls zu wünschen übrig», gibt Chi Chiu Leung zu Bedenken, ein Spezialist für Atemwegserkrankungen, der darauf hinweist, dass bei
Im Januar und Februar verhängte die Regierung 26 Zwangseinweisungen, um alle Anwohnerinnen und Anwohner eines Stadtviertels oder Gebäudes zu testen.
(C) Marc Progin 
den 26 Einsätzen im Januar und Februar nur etwa 20 Fälle entdeckt wurden. Wie Festlandchina setzt auch Hongkong auf Massentests. Überall in der Stadt wurden Gesundheitsstationen eingerichtet, in denen sich die Menschen kostenlos testen lassen können. Für bestimmte Bevölkerungsgruppen ist der Test Pflicht - eine Verweigerung wird mit 25000 HKD (2900 CHF) gebüsst und kann sogar mit sechs Monaten Gefängnis bestraft werden. «Das betrifft Menschen, die Symptome haben oder in einem Gebäude leben, in dem eine Häufung von Fällen festgestellt wurde, sowie bestimmte Risikoberufe wie Taxifahrerinnen, Kellner, Fitnessangestellte und Kosmetikerinnen, die alle zwei Wochen getestet werden müssen», führt Keiji Fukuda aus, der Direktor der School of Public Health an der Universität von Hongkong, der früher für die WHO in Genf gearbeitet hat.

\section{Virusspuren in Abwasserkanälen}

Ein von der Universität Hongkong im vergangenen Oktober initiiertes Pilotprojekt identifizierte zwei Gebäude mit Covid-19-Fällen durch die Untersuchung von Proben aus den Abwasserkanälen der Stadt. Die Bewohnerinnen und Bewohner wurden anschliessend getestet. Laut Keiji Fukuda wird diese Methode seit Jahren verwendet, um Polio-Fälle zu identifizieren. Das Ziel dieser umfassenden Tests ist es, versteckte Übertragungsketten zu identifizieren, um die Replikationsrate des Virus zu senken - die Anzahl der Menschen, die jede infizierte Person ansteckt. Ein ausgeklügeltes System zur Kontaktverfolgung begleitet die Tests. Untergebracht in einem Terminal, das normalerweise von Kreuzfahrtschiffen genutzt wird, spüren rund 200 Angehörige der Polizei, des Zolls und der Feuerwehr jeden positiven Fall durch gründliche Telefoninterviews auf. Wer mehr als 15 Minuten mit einer infizierten Person verbracht hat, ohne eine Maske zu tragen, gilt als «enger Kontakt». Wird eine solche Person identifiziert, wird sie zwei Wochen in einem staatlichen Quarantänezentrum isoliert. Fast 30000 Menschen hat dieses Schicksal seit Beginn der Pandemie ereilt. Vor Kurzem hat die Regierung zudem eine App namens Leave Home Safe eingeführt. Diese zeichnet auf dem Mobiltelefon der Benutzerin oder des Benutzers alle Orte auf, die in den letzten 14 Tagen besucht wurden. Möglich wird dies durch QR-Codes, die am Eingang von Restaurants, Büros und Geschäften installiert sind.

\section{Monatelang im Ausland festsitzen}

Die hermetische Abriegelung der Grenzen des kleinen Territoriums habe es ermöglicht, einen schwindelerregenden Anstieg der Fälle wie in Westeuropa zu vermei-

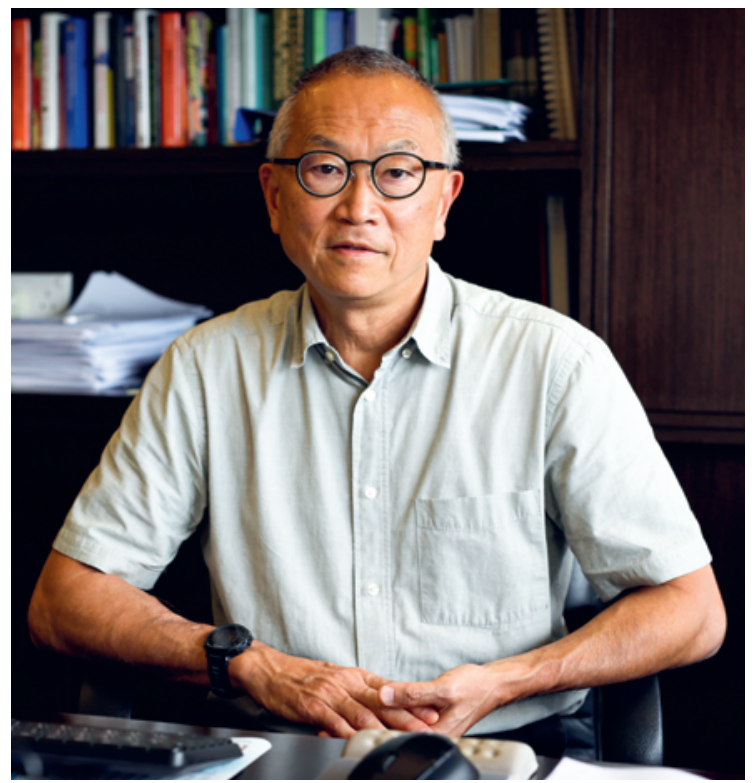

Keiji Fukuda ist Direktor der School of Public Health an der Universität von Hongkong und berät die Regierung seit Beginn der Pandemie.

(c) Julie Zaugg

den, so Keiji Fukuda. «Sobald die ersten Fälle in Wuhan gemeldet wurden, schloss die Regierung die Grenze zu China», erinnert er sich. Heute dürfen nur noch Ansässige die Grenze überschreiten und müssen sich dabei einer dreiwöchigen Quarantäne in einem der 36 von der Regierung bestimmten Hotels unterziehen.

Fukada räumt ein, dass die Massnahmen eine erhebliche Belastung für die Bevölkerung und die stark vom Tourismus abhängige Wirtschaft darstellen. «Viele Ladenbesitzer kämpfen ums Überleben, viele sind im Ausland gestrandet oder seit Monaten von ihren Familien getrennt», sagt er.

Eine Facebook-Selbsthilfegruppe für Menschen, die sich in Quarantäne befinden, ist voll von apokalyptischen Geschichten. Ein achtjähriges Mädchen wurde von seiner Mutter getrennt und zwei Wochen lang in einem Spital isoliert, nachdem es bei der Ankunft am Flughafen Hongkong positiv auf Covid-19 getestet wurde.

Trotz dieser Unannehmlichkeiten unterstützt die Mehrheit der Bevölkerung das Vorgehen der Regierung. «Der Schlüssel zum Erfolg des Hongkonger Wegs liegt in der Unterstützung der Öffentlichkeit für die von den Behörden verordneten Massnahmen", meint Chi Chiu Leung, der eine Arbeit zu diesem Thema in The Lancet veröffentlichte. Bereits im Januar 2020 setzte sich das Tragen einer Maske und das häufige Desinfizieren der Hände durch. Dadurch kam die Ausbreitung des Virus praktisch zum Erliegen. «Diese Faktoren können in jedem Land beobachtet werden, das es geschafft hat, das Virus loszuwerden", meint Leung. Als Beispiele führt er Neuseeland, Taiwan oder China an. 